\title{
Negative Dialectics of Nature: From Nature's Death to New Materialisms
}

\section{André Krebber}

Nature, stressed Raymond Williams (219), "is perhaps the most complex term in the language." The timing of this observation seems hardly a coincidence. Following Rachel Carson's Silent Spring in 1962 and even more so the publication of The Limits to Growth through the Club of Rome in 1972, the discourse around nature reached a paradigmatic intensity in the 1970s and 1980s. Neither controversies over nature, however, nor environmental catastrophe are new phenomena. Instead, they have accompanied cultures throughout most of their history. (Cf. e.g. Gloy; Mauch and Pfister) The current environmental reassessment of nature thus is as much a particular historical manifestation of an on-going occupation of humans with nature as it produces a historically specific contradiction. In the decades just before nature began to (re)inscribe itself into our collective consciousness as a sphere of concern, it was less a topic of debate and rather a pile of commodifiable material ressources, the limited availability of which was thought to have been overcome, or at least reliably brought under control. The harbouring of power from the splitting of the atom was envisioned to provide near exhaustible reserves of energy, while the green revolution was set to establish universal food security. Yet with the heavy toll that late-capitalism takes on the nonhuman environment having become alarmingly noticeable over the second half of the twentieth century, certainty about what it is when we talk of 'nature' has waned. Demarcations between the natural and the cultural have broken down, leaving us as disorientated about the world as about ourselves. The ambiguity of terminology that Williams raised seems as much a problem of its object, where something, which can neither be escaped nor held fast by us, appears to rage unruly.

Recent influential tendencies in the ecocritical discourse on nature, understood in a broad sense as the study of the environment from an interdisciplinary perspective rather than a narrow literary sense, (cf. Garrard 5) have rejected concepts of nature and culture altogether, as the dualistic thinking and its perception of the empirical world within two separate spheres they stand for has been identified as central element driving the appropriation, exploitation and transfiguration of nature by 
human societies. Dialectical philosophy was identified as a particularly guilty party. Latour (Never been modern 55), for example, concludes in his critique of modern epistemology that "dialectics makes the ignorance of that locus [between nature and culture, AK] still deeper than in the dualist paradigm since it feigns to overcome it by loops and spirals and other complex acrobatic gestures." Rather than providing a valuable critique, "the dialecticians were incontestably our greatest modernizers, all the more powerful in that they seemed in fact to have gathered up the totality of knowledge and the past and brought to bear all the resources of the modern critique." (Ibid. 57) To Latour and many others, dialectics presents the infamous climax of human hubris and self-aggrandizement. To challenge human exploitation of nature, critical environmental discourse has focused instead largely on showing that there are no two spheres of nature and culture and how the world instead is a product of endless, myriad connections, interactions, collaborations, interferences, collectives, negotiations and continuous realignments between human and nonhuman entities and the demands of their differing conditionalities. Within recent years, however, another change of tone in the discourse on nature is noticeable. Debates on object-centred ontology or those forming under the category of new materialism(s) shift the attention back from a focus on the social constructedness of nature to recovering the materiality of the empirical world (cf. e.g. Harman Guerrilla Metaphysics; Bryant, Srnicek and Harman; Dolphijn and Tuin; Morton Hyperobjects). While these perspectives mark a return to objectivity, proponents are eager to point out that this does not represent a return to old, dialectical materialisms of course, but rather a break from the anthropocentric fallacies of these older traditions, which would remain incurably dualistic, and instead a relational recovery of objectivity and materiality beyond human means and ends (Dolphijn and Tuin 93ff).

Noticeable, however, is the diametrical opposition in these approaches to reversing the masking out of the agency and autonomy of objects. Latour and others claim that it is conceptualizations such as nature, culture, object and subject that would suppress the nonhuman by essentializing the empirical phenomena they subsume. Object-centred ontologists and new materialists counter that precisely the renouncement of the object would fail to overcome such suppression while making it impossible to address moments of exploitation in social relationships with nature. (Harman Prince of Networks, 161f.) The recent countermovement 
against the surrender of the object thus can be read as a sign that dialectics might not be quite as inadequate as its critics claim. The following offers to reconcile these perspectives via recovering Theodor Adorno's negative dialectics, that is, a critique of traditional, positive dialectics, as conceptual approach to nature for the environmental humanities. Such reconciliation does not mean to come to a fixed definition of nature by identifying contrasting conceptualisations or by resolving critiques though. Quite to the contrary, it aims at placing and retaining the perspectives on nature in tension to one another. This perspective relies both on Adorno's analysis of the history of reason as well as his critique of cognition [Erkenntnis]. These will be laid out in the paper's first part. The second part advances a negative dialectical concept of nature through tracing movements in the ecocritical discourse on nature. Substantiating as much as updating Adorno's concept of nature alongside the affirmation of his dialectical approach, this essay furthers recent attempts to make Adorno's philosophy fruitful for current ecological critique (cf. for example Cook; Biro). The image of nature that ensues bears neither a simple corporeal, nor a traditional incorporeal (metaphysical) character though. Rather, nature surfaces as a field of tension marked out and mediated by material and immaterial coordinates through and through. The analysis proceeds in negative terms both on the level of the discourse and of the object: it negates the ecocritical discourse on nature while also negating a conclusive definition of nature (not, indeed, unlike current speculative tendencies, for example Morton's Dark ecology). Thus, a critical concept of nature re-emerges, conceived negatively and as radically historical. Pushing back against its various critics, dialectics, at least in its negative form, surfaces as an approach to environmental challenges, I argue, that rescues a concept of nature that allows for a critique of the domination of nature by culture without essentializing or fixating its object.

\section{Object and Apprehension}

In Dialectic of Enlightenment (DoE), Adorno and Horkheimer present a historic-philosophical reconstruction of the development of civilisation in its socio-evolutionary involvement with nature as a history of selfpreservation through human domination of nature on the grounds of subjective-instrumental, identifying reason (cf. Thyen 65). Following a 
perspective that interweaves the historical development of (instrumental) reason in general with the epoch of the Enlightenment as a particular historical phase of enlightenment, ${ }^{1}$ the authors develop the book's key concept of enlightenment as a process "aimed at liberating human beings from fear and installing them as masters" (Horkheimer and Adorno 1). Describing human history as a continuous anthropocentric struggle for mastery of nature to secure humanity's reproduction, history is characterised by the alienation of humans from nature by human practice, which manifests itself in the increasing ability of goal-oriented manipulation and thus appropriation of nature. According to Horkheimer and Adorno (184f.), "the cerebral organ, human intelligence," can be considered a special human feature in the reproduction of human life, wherein reason "acts as an instrument of adaptation" and is as such simultaneously a part of natural history and itself mediated through dialectical history. The central force accompanying humans through this history is enlightenment [Aufklärung], "understood in the widest sense as the advance of thought [... and] aimed at liberating human beings from fear and installing them as masters" (Ibid. 1). Fearful of the unknown unpredictable, enlightenment is the continuous striving of humans to make the unknown known through gradually eking out a full understanding of the world and its phenomena, thereby ultimately overcoming human fear. This tendency most clearly manifested within the period of the Enlightenment. These major themes of $D o E$ are well known, if in very different accounts. And while it has been at the margins of scholarship for some time, in recent years $D o E$ has received renewed attention, as indeed has the cultural criticism of the Frankfurt School in general (e.g. Allen; Hullot-Kentor; Jeffries; Nelson). While Horkheimer and Adorno ponder much on the results and the negative sides of the process of enlightenment and its tendency to regress into barbarism, rather than leading to a peaceful engagement both among humans and between humans and nature, $D o E$ also offers a history of how enlightenment took place. This has mainly been considered as a critique of modern science or the Enlightenment project, yet the critique developed by Adorno and Horkheimer proves double edged and reaches much deeper. (Allen)

Following Adorno and Horkheimer, the two different meanings are distinguished here through capitalisation, referring to the general concept as 'enlightenment' and the specific historical phase as 'the Enlightenment.' 
According to the analysis of enlightenment in $D o E$, humans and their specific ability to recognize and seize phenomena by concepts is shaped by engagement with the material, objective world. The human ability to reason serves herein as the faculty to grasp phenomena and make them exploitable through the deployment of concepts [Begriffe].

Like the material tool which, as a thing, is held fast as that thing in different situations and thereby separates the world, as something chaotic, multiple, and disparate, from that which is known, single, and identical, so the concept is the idea-tool which fits into things at the very point from which one can take hold of them. (Horkheimer and Adorno 31)

It is by means of conceptual thought and language that humans comprehend their environment, wherein enlightenment proves a dialectical process in which humans come to recognize the objective world through their conceptual apprehension of it. Thus, the process of human identification of the world in concepts has been one in which human reason grappled with and itself became moulded through its encounters with the phenomena that humans found themselves confronted with. This process of moulding, however, is one of disagreement:

The concept, usually defined as the unity of the features of what it subsumes, was rather, from the first, a product of dialectical thinking, in which each thing is what it is only by becoming what it is not. This was the primal form of the objectifying definition, in which concept and thing became separate, the same definition which was already far advanced in the Homeric epic and trips over its own excesses in modern positive science. (Ibid. 11)

According to Horkheimer and Adorno, cognition [Erkenntnis] proves itself as such not by the act of registering a phenomenon within a concept, but only within the transition from one conceptualization to another. The reason for this lies within both, the function the concept serves as well as the animatedness of the phenomena that terms are made to determine. As cognition ignites on the bustle of the natural world, the concept is a reflection of the unknown of the material world, that is, the potential of natural things to become different from what they are at a given time in a specific place. Proscribing a definitive conceptualization to something and 
thereby hoping to overpower this potential, the concept, however, instantaneously and necessarily meets its inadequacy within the object it is made to capture. Meant to overcome fear of the unknown by determining the very act of change, cognition now has to follow the change within the phenomena in order to maintain correspondence between object and concept and to retain the illusion of their identity. (Ibid. 10f.) Thus, enlightenment proves a dialectical process because it proceeds within this continuous attempt to identify the object, an attempt that outstripped itself when the door was thrown open to an immense increase in the material adjustment of the object to the concept during the Enlightenment. The authors, however, identify another dialectical character of enlightenment that proves cognition of something to be emancipative as well as repressive. While "freedom in society is inseparable from enlightenment thinking" in so far as it provides an emancipative potential which allows humans to evade the necessity and compulsion of nature, at the same time "the very concept of that thinking ... already contains the germ of the regression which is taking place everywhere today." (Ibid. xvi) Without reflecting upon this regressive moment, enlightenment "seals its own fate" (ibid.) and descends time and again into barbarism, as the authors witnessed during the time of writing these lines with the Second World War, the catastrophe of the Shoah and the destruction of Hiroshima and Nagasaki by atomic bombs.

Adorno further explored this regressive moment as the simultaneous compulsion and insufficiency of the ideational act. According to him, thinking is subjected to an aporia between its own requirement to be tied to the act of identification on the one side, and the distinctiveness of concepts and things on the other (Adorno Negative dialectics 5). Whereas concepts require the empirical substrate on which they are formed and upon which they reflect - otherwise they would remain empty and arbitrary - thought can only reflect by identifying these substrata. Yet any reproduction remains a reproduction of the thing represented, not the complete, historical, empirical thing itself. As a consequence, thinking inherits a contradiction between its concepts that claim identity, and those qualities of the empirical world that fail to incorporate within the concepts. (Cf. Schweppenhäuser 47) Without reflecting on this contradiction, the process of identification "unavoidably ruptures the actual identity of the objects of thought and subordinates them to the identity principle of the reasoning subject" (ibid. 41). Thus 'nature' 
solidifies into a firm and finite constant. Adorno's negative-dialectical philosophy now provides the necessary reflection through demonstrating the immanent failure of thinking, that is identifying, and thereby disproving presumptions of the reasoning subject's primacy over the object of knowledge. As a consequence and without simply reversing the hierarchy between subject and object and thus surrendering the subject to the primacy of the object, as Adorno's claim for 'Vorrang des Objekts' often is translated, he calls instead for giving priority to the object in the cognitive process (Adorno "On subject and object" 250-1). Such priority means that instead of declaring the prerequisite of the conscious and thinking subject in defining the objects, and thus essentially reducing the particular objects to general concepts, thinking has to entrust itself to the guidance of the particular objects. (Thyen 1989, 208-10) The lever that achieves this within negative dialectics is to switch the inherent "direction of conceptuality" (Adorno Negative dialectics 12) from identifying the general with the particular over to the identification of the particular with the general. Thereby, thinking receives "a turn towards the nonidentical. ... Insight into the constitutive character of the nonconceptual within the concept would end the compulsive identification which the concept brings unless halted by such reflection." (Ibid., trans. mod.) By way of the concept through which it is enacted, cognition has to recover that what distinguishes particular empirical things from one another and makes them unique, by protecting this particularity - Adorno's nonidentical - from its subordination to the commonalities of general concepts, and not as "a spiritual substance in contradistinction to the material world but [as] the complex concatenation of nature in contrast to its individual link." (Horkheimer and Adorno 10)

Thinking aims to recognize its objects by identifying what is essential in them. Yet, as Adorno shows, it is precisely this project that the process of identification itself ensures will fail. It falls short of its aims because it can always only define its objects as examples of something else, something general. But then it fails to say what the objects themselves are. The fact that conceptual thinking - and there is no other kind - cannot positively define what is non identical in objects of knowledge is the expression of an objective aporia. For Adorno, the nonidentical is not an 'affirmative' concept that could be given definition, beyond the limits of rationality through 'other,' nonrational 
modes of thinking. ... It is the conceptually negative result of the defined negation of the notion of identity. (Schweppenhäuser 46f.)

From this conundrum of thinking as oppression, Adorno recovers the possibility of reconciliation between subject and object, spirit and material world, human beings and things, human and animal, culture and nature that consists in an acceptance of the object's nonidentity and of the subject's inability to ever capture it. The distinctiveness and fundamental difference of his philosophy from most other current philosophies hence manifests within his reliance on recovering the diversity, difference and heterogeneity of the empirical world from thinking's identifying constraint. Commonly, such as in the case of Latour, the source of oppression and domination is located within the act of perceiving, for example, humans and animals as different. As a consequence, the focus is directed at the essential correspondence and equal value among humans and objects, humans and things, or culture and nature in order to challenge the hierarchy between them, declaring thereby however any difference(s) insignificant. Adorno's mainspring to overcome domination, in contrast, is accentuation, recovery and acceptance of the other's very individual difference.

To work towards reconciliation, negative dialectics urges thinking to immerse

itself in its objects, to assure itself of the objects' qualitative elements, in the knowledge that it cannot resolve them in consciousness. Part of cognition in this sense is that the objects' recognition does not exhaust them. The nonidentical is not the unaccounted rest of cognition, but an essential element of objects, in the sense that it emerges as an instance of protest against claims of totality of the conceptual-identical. (Thyen 210)

Rather than the nonidentical merely representing a surplus of the objects that escapes identification in concepts, Adorno locates the tension between identity and nonidentity that surfaces in the constellation of concepts, cognition and the subject as having its source within the objects themselves as well as the subjects. Nonidentity not simply contradicts the identical among things, but forms a dialectical relationship within the object. As a consequence, his point is not to make objects exhaustively 
determinable by extending our knowledge with a category of the nonidentical that would arrest what exceeds our knowledge of the object within a concept nonetheless - a point, in which it differs from Kant's thing-in-itself (Adorno "On subject and object"; Pradler 87-90). Rather, the objects prove themselves mediated between identity and non-identity, and therefore not simply nonidentical from one another, but nonidentical within themselves; objects, according to Adorno, are dynamic due to the tension between their identity and non-identity with an other; between the general and alike, and the particular and differentiated; between being an exemplar of a species, and an individual - and are therefore never finitely fixed but historically moved (Adorno Einführung Dialektik; Thyen 213ff.). As such, Adorno's nonidentical does not refer to any metaphysical entities or elements of or within the objects, but the nonidentical describes the objects' potentiality to be something different than what they are at a specific time and place, a potential in which they negate themselves.

Since the dialectical thus is placed within the objects, the process of comprehension turns from devising a complete, finite system of knowledge into an endless tracing of the negating tension between identity and nonidentity, without synthesis - an open dialectic. The place for such cognition is experience:

Cognition that wants to recollect [Eingedenken] the nonidentical through priority of the object can be conceived with Adorno as a specific form of experience. ... Meant is a discursive, that is, an experience guided and determined by reflection, which is gained from a kind of acquisition of possible objects of reflection that preserves the insoluble of the object as its freedom. (Thyen 213)

However, the nonidentical's recollection "is not to be obtained directly, as something positive on its part, nor is it obtained by a negation of the negative" (Adorno Negative dialectics 158). To redeem the potential of reconciliation, rather than to appropriate and assimilate, the task of cognition is neither to chase the complete determination of the objects of knowledge, nor to surrender their logical, rational examination and classification. Even less is it a question of positivistic determination and measuring, even if it continues to rely on and accept the insights of positivist science. Instead, cognition is required to reach through our identifying, conceptual knowledge and beyond the objects' determination 
by concurrently remembering the inadequacy of our conceptual knowledge to fully permeate the objects of knowledge, and inscribe this remembrance into our knowledge. (Adorno Einführung Dialektik 12 \& 164ff.) We become cognisant of the nonidentical "through overcoming the hypostasizing of classificatory conceptual structures that are often substituted for the materiality they represent" (Schweppenhäuser 47, emphasis added). Determining an object, therefore, becomes a question of turning conceptual identification upon itself, negating definitive and conclusive definitions by confronting them with their own inadequacy and by insisting on determining an object through its continual progressing. By inscribing the concept's limitation into classificatory structures, it becomes possible to keep the process of cognition open and historically evolving alongside objects, thus capturing their becoming [werden] (Buck-Morss; Thyen 215ff.). Yet it is exactly by such negation that cognition becomes exact, as it honours and recollects the transitional character of its object and thereby approximates it more accurately.

\section{Tracing Ecocritical Dialectics}

Since the 1960s, a thick and controversial ecocritical discourse has spun around nature. Tracing the twists and turns of this debate via a selected handful of iconic ecocritical works and theoretical positions as steppingstones, reveals a trajectory that confirms Adorno's portrayal of cognition as a reflexive movement upon its object - the discourse indeed can be shown to manifest itself not as a meandering from one possible meaning to another, or simultaneous readings of equal plausibility that would provide an ambiguous and incoherent image of nature, but as dialectical turns upon contradictory conceptualisations of nature. The trail allegedly picks up with the gypsy moth, or rather, its devastation. Often cited as having had a significant impact on the environmental movement of the 1960s and hence a new awareness of nature as a topic of concern is Rachel Carson's study on the effects of pesticides on the environment. Not the least because of a concerted and high-profile promotion campaign and its serialisation in The New Yorker, (Lear 377ff.) the resulting book Silent Spring proved highly successful and was translated into several different languages in the decade following it's publication. DDT (dichlorodiphenyltrichloroethane), the study's central villain, was part of the green revolution in agriculture that was intended to provide global 
food security through concerted development and widespread distribution of technologies such as modern irrigation systems, pesticides, fertilizers and crop improvement. In contrast to these idealistic hopes, Carson showed the negative effects of pesticides on the environment, especially the disappearance of songbirds, claiming a connection between this disappearance and the deployment of synthetic pesticides. (Carson) Such marks a decisive change in the way nature was perceived. Driven by hopes that evermore modification would increase the productivity of nature endlessly, in the 1940s and 1950s nature featured prominently as material that was taken more or less for granted and fixed. Silent Spring showed nature instead as exhaustible and vulnerable, highlighting the intrinsic emotional pleasures we value in our relation with natural entities and making nature's materiality visible as something fragile and not just universally given. The Limits to Growth (Meadows et al.) addressed the issue ten years later at a global stage. Its simulation of the interrelational effects of changes in world population, industrialisation, pollution, food production and resource depletion on the systemic development of the earth highlighted the limits in sustainability of human modes of production.

Both studies, of course, equally were challenged for their supposedly political intentions and their scientific validity (Bardi; Murphy). And whereas Silent Spring is often considered as decisive spark for the emergence of the environmental movement of the 1960s and 1970s, it is The Limits to Growth that proves more widely cited and influential in the environmental discourse than the former (cf. Heise). However, neither text is being referred to here for its actual or alleged contribution to the emergence of environmental movements or environmental studies, but as markers for the particular way nature as an entity of cultural concern and perception re-entered into the socio-cultural consciousness. As such, they stand for the surfacing of a contradiction within human experience of the non-human environment, upon which the renewed discourse on nature followed. With the green revolution and the entering of the atomic age, nature had been considered mastered and the natural limits to human reproduction overcome, at least in two crucial areas, energy consumption and food supply. Carson's account of the effect of DDT on bird populations and the limitation of the exploitation of the earth's ecosystem by Meadows et al. suggested in contrast how nature was anything but controlled and instead heading towards collapse. Silent Spring as well as 
The Limits to Growth can be read as symptoms of these environmental experiences, that reflect how nature re-inscribed itself into the cultural consciousness both as a historically decisive and global issue as well as in the perception of nature as a waning and limited resource, and victim of human domination.

That these first signs of a changed assessment of nature emerged most prominently within a scientific context and were initially driven by positivist, scientific inquiries, seems little surprising. After all, the vulnerability and limitedness of nature as a resource contrasted starkly with the popular, dominant, positivistic scientific concept of nature as a determinable and predictable contingency. Quickly, however, these initial efforts switched on a theoretical level to the critique of science and its interpretation and determination of nature. The scientific evaluation was followed by a re-appraisal of what we mean by 'nature,' both in itself and in relation to human societies. In particular, naturalistic approaches formed the focus of early environmental criticism, through critiques of science's materialistic reductionism, the degradation of nature to a mere material resource for human production and consumption alongside a recovery of the ecological, organic qualities of nature, and the epistemological appropriation of nature in general. ${ }^{2}$ (Kropp) In stark contradiction to the scientific materialism of the $1950 \mathrm{~s}$, advancing degradation moved nature increasingly into sight as a living, if disappearing or retreating organism. Few theses make this more palpable than the one on the death of nature developed by Carolyn Merchant in her book of the same title in 1980. Providing a re-evaluation of the rise of science as dominant means of studying and appropriating nature alongside the rise of capitalist market-culture in the sixteenth and seventeenth century, it highlights the undermining of the idea of nature as a living, independent and self-organising realm by the mechanistic worldview of the scientific revolution. (Merchant)

Against the background of environmental experiences of the 1960s and 1970s, Merchant's reinterpretation of early modern science vividly reveals

\footnotetext{
${ }^{2}$ Positivistic, naturalistic approaches, of course, never disappeared, (cf. Gloy vol. 1) and probably even remained dominant throughout the decades discussed here. Instead, what is traced here, is the somewhat modernizing, avant-garde spearhead of ecological and environmental critique, which questioned the conceptualisation of nature ahead and thus represent the enlightening development in Adorno and Horkheimer's sense.
} 
how historical inquiries are shaped through current experiences. But the book's popularity also reveals something about the intellectual mediation of this current experience. At the time when Merchant wrote Death of Nature, it became increasingly apparent that nature not only did not provide unlimited resources - the loss of human control ${ }^{3}$ also proved nature in one way or another a realm of activity and productivity in its own right. This activity revealed itself in two contradictory respects: in the form of a threat - for example nuclear fission spinning out of control - as well as a threatened mode of production upon which humans were dependent for their own future and which, it seemed, they proved unable to replicate through technology while becoming increasingly incapacitated. The Death of Nature both made science visible as the original culprit of the disappearing of nature that Merchant was witnessing during her own time (a process started during the Enlightenment but only coming into full effect and showing its full consequence then), and presented a metaphor for what was happening to nature under latecapitalism. Realizing not only the limitation of natural resources but also the dependency of human culture upon nature as a producing principle of those resources and humanity's vulnerability, nature was turned into a subject and re-described as an independent, self-acting organism that could die (and consequently be murdered by science and capitalism). Invocation of the image of nature's dying provides thereby a negative reflection within knowledge of the experience of an agency that seemed beyond human appropriation.

The Death of Nature was a result of as much as presenting a significant contribution to ecofeminist discourse, which proved so influential and prominent in critical assessments of nature throughout the ecological debates of the 1980s. Driven by feminist concerns about nature that were evinced through highlighting the connection between the oppression and discrimination of women and domination of nature by male culture, ecofeminism's response to the oppression by practicing solidarity with nature as fellow dominated entity coincided with a re-spiritualisation of a holistic, organicist nature. (Garrard 26-31) The social constructivist perspectives that gained increasing foothold in the 1980s and 1990s criticised exactly such charging of nature as an individual actor that one

\footnotetext{
${ }^{3}$ The nuclear accident at Three Mile Island (USA) in 1979 made this particularly obvious, whereas Chernobyl (Ukraine) in 1986 cemented this experience of lost control further and remains eponymous to this day.
} 
could act in solidarity with, or that could die as a whole, (alongside the evincing of a special connection and bond between nature and women) as idealist and, especially, essentialist. (Carlassare; Armbruster) Thus, the social constructivist perspective is as much a widening and refining of the critique of science from the level of practical to intellectual appropriation (and in this respect a continuation of previous ecocriticism) as it is a critique of ecocritical discourse. Although it remains debatable if ecofeminism per se was indeed essentialist in this sense and claimed such a special interconnectedness between women and nature throughout, (Carlassare) social constructivist critique marks a decisive rupture in the discourse on nature. Highlighting 'nature' as an illusory intellectual production that unjustifiably united incoherent phenomena under one broad term in the first place, it shifted the discourse's focus away from actual, objective, material nature to the level of its appropriation in language (cf. Braun and Wainwright).

Contrary to the widespread polemics, social constructivists did not, of course, denounce the existence of physical phenomena as such (Burningham and Cooper). Rather, their criticism emphasised that any perception of such phenomena is already and always mediated by the social pre-structuring of human experience, and as such neither something that is outside of nor in opposition to culture. As a consequence, phenomena are also not perceivable independently from such prestructuredness. There is no immediate access to nature according to social constructivist critique, as naturalistic, positivistic, science-based accounts fundamentally, if not always explicitly, suggest. Both culture and nature are for better or worse mediated through one another, rendering any ideational separation of the world into these two spheres false. Moreover, it is this type of thinking in dualistic oppositions that an ecocritique informed by social-constructivism considered instrumental in the continuing unsustainable modification, exploitation and oppression of the nonhuman world. (Braun; Bird) Indeed, evermore diversifying environmental inquiries into the environment and the growing realisation of the extent to which culture and nature are intertwined and interdependent made the idea of nature as a unified entity in itself increasingly untenable. The widespread rejection of such charged and overburdened concepts as nature and culture alongside calls to focus on 
the ambiguities and ambivalences of phenomena ${ }^{4}$ represent the sediment of such experience. (Demeritt) Critiques of nature (and, at the same time, culture) pointed instead towards the diversity and incongruity of the concept with its object. What was previously perceived as the individual spheres of nature and culture disintegrated as a consequence into various alternative constructions, thus diversifying and expanding the description of the world into an indefinite multiplicity of discursive constructions.

Considering the central role the term nature occupies in (the selfacclamation of) human cultures and their history, the vicious responses to such sweeping dismissals and radical derailments from the 1990s to the present seem little surprising. ${ }^{5}$ Yet there is more at stake in such responses than insulted human hubris. Judith Butler's Gender Trouble (1990) has become iconic for the controversy between social constructivist and materialist oriented positions. For a book laden with psychoanalytical theory, it was exceptionally successful and just as viciously criticised, mocked and ridiculed. Although not actually concerned with nature and ecological discourse, but rather with the instability of human biology in relation to the construction of social identities, the book and its sequel Bodies that Matter (1993) nevertheless negotiate the same contested terrain of pre-cultural nature while marking a revealing tension at the discourse's centre. Butler's critique in Gender Trouble of biological sex as a stable category, which is culturally re-constructed as gender within the social sphere, suspended the clear separation between the two categories and instead argued that both gender and sex are a result of constant cultural performances and constructions. (Salih 55-59) Such dissolving of any material point of reference into mere performativity exemplifies, according to critics, how the radical questioning of the possibility to perceive any such entity as material nature outside of its social construction would privilege the social discursiveness of material nature and make the actual, empirical object of reference disappear from sight. Instead, social constructivist discourse would operate in ignorance and disregard of its empirical object, leading to random talk that allegedly would construct the object at will and eventually overwrite it completely. (Gandy; Sayer; for a discussion of social constructivism in relation to 'nature' cf. Kropp 73)

\footnotetext{
${ }^{4}$ Such a perspective is indeed not unlike Adorno's understanding of immanent critique, if with almost oppositional consequences. (Zuidervaart)

${ }^{5}$ Most prominently, they are possibly represented by the Sokal affair.
} 
Butler's response to the criticism via Bodies That Matter: On the Discursive Limits of "Sex" (1993) now somewhat unexpectedly confirms to a certain degree such complaints about the obliviousness to the material. Already the book's title recovers physicality and materiality of bodies in addition to the performativity of discourses, thus levelling the discourse's immateriality with some form of prelinguistic materiality. Of course, rather than merely acknowledging such relevance of materiality, Bodies That Matter develops a much more complex and refined argument, in which materiality is not recovered as a stable point of reference, but as something that constantly provokes redefinition and serves as embodiment of the repetition and iterability of performative acts. Rather than retracting, the book aims to clarify and further develop some of the issues explored in Gender Troubles. (Salih 59-62) Yet it is especially the continuity between the works according to which Bodies That Matter embodies an intellectual countermove to the emphasis on the social construction of physical phenomena that complements the argument on performativity of the cultural with the performativity of matter. It seems as if Butler's radical deconstruction and liquefaction of the biological, 'natural' foundations of identities in Gender Troubles provoked a recovery of materiality, and not just as a response to her critics but as a complementary principle to her own concept of performativity. In its most rudimentary notion, then, Bodies That Matter represents a rehabilitation of the material through making visible the stabilising effects of the discursiveness on the body and vice versa. Reflecting Adorno's claim that reason proceeds dialectically, Butler's books (and in some respect also the controversy that surrounds them) mark the two sides of a dialectical turning point, in which the radical accentuation and focus of the immaterial in form of the discourse, for which both the thesis of nature's death as well as 'nature's' constructedness stand, lapsed into the materiality and physical givenness of nature. In other words: Having set out to oppose the disappearance and death of nature (a motive that also fuels the social constructivist critique of the discourse on nature), a consistent application of its critique actually loses its critical potential and lapses back into the affirmation of culture's undermining of nature that fuelled the concept's re-evaluation in the first place.

Bruno Latour's influential place in efforts to recover the referent of the discourse and its materiality in the 1990s can hardly be overstated, considering the prominence of his seminal We Have Never Been Modern 
(1993). His rejection of the reliability of terms such as nature and culture, object and subject, the defence of which usually proves the sticking point for critics of social constructivism, often leaves him superficially criticised as a radical social constructivist, who also would dissolve any material givenness outside of the discourse into thin air. But the issue of Latour's constructivism is much less straight forward than these critiques imply (cf. Harman Prince of Networks). For Latour ("Coming out" 602) "constructivism was, well, constructive, not destructive," whereas "the unfortunate addition of the word 'social', as in 'social construction', introduced a bias that has taken me 20 years to redress." He indeed flips social constructivist critiques of 'nature' from negative to positive. His figure of circular reference, deduced from his empirical studies of science in his book Pandora's Hope and expanded to other areas of knowledge production in his latest project Modes of Existence, re-establishes the social construction of factual knowledge, with empirical science being one of the areas of such constructions, as a way of recovering the agency of nonhuman objects from their appropriation by epistemological discourse. (Schlechtriemen) Through the individual steps of the empirical determination of an object such as the rain forest of Boa Vista, Latour claims, a representative understanding of the object would shape, because each individual deduction returns time and again to the empirical object of inquiry. Thus, the object of inquiry is never removed farther from its representation than one step of translation. As a consequence, the further scientists progress in their determination of an object of inquiry, the fuller its understanding would be, at least as long as one stays with the scientists and their practical work of assessment. For this reason, the construction of knowledge for Latour represents individual pieces of an object of knowledge, which in fact present an adequate understanding and representation of it. (Latour Pandora 24-79)

If Butler's books, then, mark either side of a dialectical turning point in the progression of an ecocritical discourse, hinting at the tipping point in the space between them, Latour occupies the space of the tipping point itself. The realm of a pre- or non-cultural being re-emerges from its discursive construction as autonomous agency of things and matter. Moving through the act of construction, Latour interprets the process of construction as a co-constitutional effort of the objects of knowledge and the knowing subject, in which the object inhabits the decisive, rather than subordinate position, as it guides the process of knowledge production. 
Latour recovers, against the focus on (theoretical) discourse, the materiality both of the objects of inquiry as well as of the social construction of knowledge, the latter in the form of research practices. While Latour thus exposes things and matter as active agents - nonhuman actors - in the production of the world, he accesses their agency by focusing on the space - the middle, in his terminology - between subject and object and the processes and practices of mediation. (Latour Never been modern 37) Neither recovering the object or subject in-themselves, he focuses on the effects that different actors exert on one another, claiming to thereby symmetrically map the co-constitution of the world by human and nonhuman entities. Yet it is exactly here that most of the criticism of Latour's version of actor-network-theory arises, as this very shift removes in its compartmentalisation any sign of widespread domination and suppression of nature by humans (e.g. Gamm; Noys; Winterfeld 367).

At this point intervene object-centred ontologies, speculative realism and new materialism, which represent the latest, most current (or avantgarde) stage the movement of ecocritical discourse has attained. While the differences in the approaches cannot be adequately considered here, it suffices to emphasise in this broad-brush reconstruction of ecocriticism's progression that they are united by a concern for or interest in the distinctiveness and materiality of objects (Bryant, Srnicek and Harman; Dolphijn and Tuin; Harman Immaterialism; Shaviro). Both object-centred ontology as well as new materialism aim not only at making visible the agency of the nonhuman world through discourse and (new or revised forms of) representation, but at recovering the object and its materiality (e.g. contributions in Coole and Frost). New materialist proposals to make the ambiguity of matter, that is, its imperceivability and indeterminability, productive for criticism, especially move the focus away from a preoccupation with discourse. Instead, matter and its physical agency, independence and ambiguity are highlighted as focal points of analysis. At the same time, however, new materialists point out that they are careful not to fall back behind social constructivist critiques of the mediatedness of our experience and cognition of the objective world or reaffirm an unreflected anthropocentric perspective. Intending to move through social constructivist critiques while simultaneously reclaiming the vibrancy and agency of matter as a forgotten and disregarded aspect of reality, new materialism dissociates itself from old, positivist scientific and dialectical 
materialism. Contrary to these latter traditions, it proposes to make visible the partaking of matter in shaping the discourse and to let matter infiltrate and direct a reconstruction of our ways of knowing and seeing the world. Rather than reengaging the discursive construction and representation of the material world, new materialists attempt to restructure the discourse around and allow the discourse to be restructured by the object and matter. Within the context of ecocritical discourse, these critics thus continue the refocusing from the discursive construction of nature to a reconsideration of its material presence and givenness that was a reaction to the overemphasising of the discourse over the object.

\section{Tracing Nature}

The ecocritical discourse of nature seems to be propelled forward by a productive tension between corporeal and incorporeal moments that surfaces within it. Whereas on the one hand a continuous development towards a recovery of 'nature's' particularity and agency emerges, on the other hand the discourse oscillates between material and immaterial qualities. The motives of nature's disappearance and its death in Silent Spring, The Limits to Growth and The Death of Nature alongside tendencies to spiritualise nature in early ecofeminism, emphasised the consideration of 'nature' as a material resource in contrast to an immaterial, productive moment in what Adorno ("Natural History" 253) described as "fatefully arranged predetermined being." Especially in The Death of Nature and ecofeminism nature features as an incorporeal phenomenon. Attempts by social constructivism to provide nature with room to breath again by criticising and deconstructing the construction of nature in language and as a unified whole further revealed the extent to which the pre- or non-cultural is fluid, shifting, transitional and interrelational. Yet pushing the constructivist perspective to its logical conclusion, the discourse eventually reacted by lapsing back into the explicit reconsideration and recovery of 'nature' as an object and its materiality. Attempts to identify nature as one or the other appear to lead instead to its opposite: perceiving it as fixed, unified corporeality highlights its incorporeal, changing and inconstant quality, whereas identifying an incorporeal element of nature, or, rather, the identification of this element as 'nature,' provokes again the affirmation of its corporeal givenness. In this, the discourse's progression reflects Adorno's 
reconstruction of cognition as a dialectical movement upon its object that is a result of the insufficiency and limitations of conceptual, identifying thinking in fully and conclusively capturing its objects. Reading the ecocritical discourse through Adorno's negative dialectics thus provides a starting point for negotiating the complexities Raymond Williams identified in the term 'nature' by representing a reflexive movement upon its object.

According to negative dialectics, the discourse responds to experiences of its object that contradict its conceptual appropriations, which surface as immanent contradictions within the concepts themselves. Tracing the twists and turns of the conceptual discourse hence functions indeed as a corrective for a solidifying identification of its object. The conceptual movement, represented within the discourse, becomes a reflection of the movement of the phenomenon itself; it is a manifestation of the object forit-self. As such "the idea is to its phenomena [sic.] as is an expression to a face: the idea is expressive." (Hullot-Kentor 246) From this perspective then, tracing the ecocritical discourse evinces a conceptualisation of nature, which does not have to reduce its object to either corporeality or incorporeality, but detects it as the tension between these two. Rather than a solid entity, nature surfaces as a formal principle that appears in an open dialectical movement between instances of material manifestation and presence, and immaterial aspects of productivity, agency and change. Negativity proves decisive for this movement in two respects that necessarily contradict each other. As the material manifestations change, matter as something fixed becomes negated, whereas the effects manifesting in the material negate change. Yet this also means, that there is neither a starting point that would privilege the one over the other, nor is there an endpoint to the movement. Instead, nature surfaces as historically open and constantly changing: it requires both elements matter and change. Without change there would be no nature, as objects would be mere matter, whereas change requires matter to come into existence. Thus instead of nature being either fixed materiality or immaterial self-activity, it is change impacting upon and through the material, the interactions between materials that constitute nature independent yet intertwined with culture. As a consequence, however, nature also is determinable only negatively, that is, in its material manifestation only after it took place and thus in its absence. Only by tracing instances of material manifestations can we become aware of 
nature, thereby negating both the fixedness of matter, while also evincing only a negative image of nature. Thereby, a negative dialectical concept of nature not only allows accounting for the complexity of the term and the discourse on nature, but also recovers 'nature' as a critical concept to resist human claims of appropriation without essentializing its object.

\section{References}

Adorno, Theodor W. Einführung in die Dialektik (1958). Ed. Theodor-W.Adorno-Archiv. 1. Aufl. Berlin: Suhrkamp, 2010

---. "The Idea of Natural History." Trans. Hullot-Kentor, Robert. Things Beyond Resemblance: Collected Essays on Theodor W. Adorno. Ed. Hullot-Kentor, Robert. New York: Columbia University Press, 2006. 252-70

---. Negative Dialectics. Trans. Ashton, E. B. London: Routledge, 1990

---. "On Subject and Object." Trans. Pickford, Henry W. Critical Models: Interventions and Catchwords. Adorno, Theodor W. New York: Columbia University Press, 2005. 245-58

Allen, Amy. "Reason, Power and History: Re-reading the Dialectic of Enlightenment." Thesis Eleven 120.1 (2014): 10-25

Armbruster, Karen. "Blurring Boundaries in Ursula Le Guin's 'Buffalo Gals, Won't You Come Out Tonight' A Poststructuralist Approach to Ecofeminist Criticism." ISLE 3.1 (1996): 17-46

Bardi, Ugo. Limits to Growth Revisited. New York: Springer, 2011 Biro, Andrew, ed. Critical Ecologies the Frankfurt School and Contemporary Environmental Crises. Toronto: University of Toronto Press, 2011.

Braun, Bruce. "Nature and Culture: On the Career of a False Problem." $A$ Companion to Cultural Geography. Eds. Duncan, James S., Nuala Christina Johnson and Richard H. Schein. Malden, MA: Blackwell, 2004. 151-79

Braun, Bruce, and Joel Wainwright. "Nature, Poststructuralism, and Politics." Social Nature: Theory, Practice, and Politics. Eds. Braun, Bruce and Noel Castree. Malden, MA: Blackwell, 2009. 41-63

Bryant, Levi R., Nick Srnicek, and Graham Harman, eds. The Speculative Turn: Continental Materialism and Realism. Melbourne: Re.press, 2011 
Buck-Morss, Susan. The Origin of Negative Dialectics: Theodor $W$. Adorno, Walter Benjamin and the Frankfurt Institute. Hassocks: Harvester Press, 1977

Burningham, Kate, and Geoff Cooper. "Being Constructive: Social Constructionism and the Environment." Sociology 33.2 (1999): 297316

Butler, Judith. Bodies That Matter: On the Discursive Limits of "Sex". New York; London: Routledge, 1993

---. Gender Trouble: Feminism and the Subversion of Identity. New York; London: Routledge, 1990

Carlassare, Elizabeth. "Destabilizing the Criticism of Essentialism in Ecofeminist Discourse." Capitalism Nature Socialism 5.3 (1994): 5066

Carson, Rachel. Silent Spring. Greenwich, CT: Fawcett Publishing, 1962 Cook, Deborah. Adorno on Nature. Durham: Acumen, 2011

Coole, Diana H., and Samantha Frost, eds. New Materialisms: Ontology, Agency, and Politics. Durham, NC; London: Duke University Press, 2010

Demeritt, David. "What is the 'Social Construction of Nature'? A Typology and Sympathetic Critique." Progress in Human Geography 26.6 (2002): 767-90

Dolphijn, Rick, and Iris van der Tuin, eds. New Materialism: Interviews \& Cartographies. Ann Arbor, MI: Open Humanities Press, 2012. Print.

Bird, Elizabeth Ann R. "The Social Construction of Nature: Theoretical Approaches to the History of Environmental Problems." Environmental Review: ER 11.4 (1987): 255-64

Gamm, Gerhard. "Menschliche und nichtmenschliche Wesen: Zur Wissenschafts- und Technikforschung von Bruno Latour." Rechtshistorisches Journal 20 (2001): 136-61

Gandy, Matthew. "Crumbling Land: The Postmodernity Debate and the Analysis of Environmental Problems." Progress in Human Geography 20.1 (1996): 23-40

Garrard, Greg. Ecocriticism. London; New York, NY: Routledge, 2012 Gloy, Karen. Das Verständnis der Natur. 2 vols. München: C.H. Beck, 1995-6

Harman, Graham. Guerrilla Metaphysics: Phenomenology and the Carpentry of Things. Chicago: Open Court, 2005 
---. Immaterialism: Objects and Social Theory. Theory Redux. Cambridge: Polity Press, 2016

Harman, Graham. Prince of Networks: Bruno Latour and Metaphysics. Melbourne: re.press, 2009. E-book.

Horkheimer, Max, and Theodor W. Adorno. Dialectic of Enlightenment: Philosophical Fragments. Trans. Jephcott, Edmund. Stanford, CA: Stanford University Press, 2002

Hullot-Kentor, Robert. "Introduction to Adorno's 'The idea of naturalhistory'." Things Beyond Resemblance: Collected Essays on Theodor W. Adorno. New York, NY: Columbia University Press, 2006. 234-51 Jeffries, Stuart. Grand Hotel Abyss: The Lives of the Frankfurt School. London, New York, NY: Verso, 2017

Kropp, Cordula. "Natur": Soziologische Konzepte politische Konsequenzen. Opladen: Leske+Budrich, 2002

Latour, Bruno. "Coming out as a philosopher." Social Studies of Science 40.4 (2010): 599-608

---. An Inquiry Into Modes of Existence: An Anthropology of the Moderns. Cambridge, MA, London: Harvard University Press, 2013

---. Pandora's Hope: Essays on the Reality of Science Studies. Cambridge, MA: Harvard University Press, 1999

---. We Have Never Been Modern. Trans. Porter, Catherine. Cambridge, MA: Harvard University Press, 1993

Lear, Linda. Rachel Carson: Witness for Nature. Boston, MA: Mariner Books, 2009

Mauch, Christof, and Christian Pfister, eds. Natural Disasters, Cultural Responses: Case Studies Toward a Global Environmental History. Lanham, MD: Lexington Books, 2009

Meadows, Donella H., Dennis L. Meadows, Jørgen Randers andWillam W. Behrens III. The Limits to Growth: A Report for the Club of Rome's Project on the Predicament of Mankind. New York, NY: Universe, 1972

Merchant, Carolyn. The Death of Nature: Women, Ecology, and the Scientific Revolution. San Francisco, CA: Harper \& Row, 1980

Morton, Timothy. Dark Ecology: For a Logic of Future Coexistence. New York, NY: Columbia University Press, 2016

---. Hyperobjects: Philosophy and Ecology After the End of the World. Minneapolis, MI: University of Minnesota Press, 2013 
Murphy, Priscilla Coit. What a Book can Do: The Publication and Reception of Silent Spring. Amherst, Boston, MA: University of Massachusetts Press, 2005

Nelson, Eric S. "Revisiting the Dialectic of Environment: Nature as Ideology and Ethics in Adorno and the Frankfurt School." Telos 2011.155 (2011): 105-26

Noys, Benjamin. "The Density and Fragility of the World: Latour." The Persistence of the Negative: A Critique of Contemporary Continental Theory. Noys, Benjamin. Edinburgh: Edinburgh University Press, 2012. 80-105

Pradler, Andreas. Das monadische Kunstwerk: Adornos Monadenkonzeption und ihr ideengeschichtlicher Hintergrund. Würzburg: Königshausen \& Neumann, 2003

Salih, Sarah. Judith Butler. London, New York, NY: Routledge, 2003

Sayer, Andrew. "Postmodernist Thought in Geography: A Realist View." Antipode 25.4 (1993): 320-44

Schlechtriemen, Tobias. "Akteursgewimmel. Hybride, Netzwerke und Existenzweisen bei Bruno Latour." Das Andere der Ordnung: Theorien des Exzeptionellen. Eds. Bröckling, Ulrich, et al. Weilerswist: Velbrück Wissenschaft, 2015. 149-68

Schweppenhäuser, Gerhard. Theodor W. Adorno: An introduction. Durham, NC: Duke University Press, 2009

Shaviro, Steven. The Universe of Things: On Speculative Realism. Minneapolis, MI: University of Minnesota Press, 2014

Thyen, Anke. Negative Dialektik und Erfahrung: Zur Rationalität des Nichtidentischen bei Adorno. Frankfurt am Main: Suhrkamp, 1989

Williams, Raymond. Keywords : A Vocabulary of Culture and Society.

New York, NY: Oxford University Press, 1985

Winterfeld, Uta von. Naturpatriarchen: Geburt und Dilemma der Naturbeherrschung bei geistigen Vätern der Neuzeit. München: oekom, 2006

Zuidervaart, Lambert. Social Philosophy After Adorno. Cambridge, New York, NY: Cambridge University Press, 2007 